Review Article

\title{
Beta-Glucans as a therapeutic agent: Literature Review
}

\author{
Eric Francelino Andrade* and Débora Ribeiro Orlando
}

Institute of Agricultural Sciences, Federal University of Jequitinhonha and Mucuri Valleys, Unaí Minas Gerais, Brazil

\section{Article Info}

\section{*Corresponding author: \\ Eric Francelino Andrade}

Institute of Agricultural Sciences

Federal University of Jequitinhonha and Mucuri Valleys

Unaí Minas Gerais

Brazil

E-mail: ericfrancelinoandrade@gmail.com

Received: October 29, 2018

Accepted: November 26, 2018

Published: December 3, 2018

Citation: Andrade EF, Orlando DR. BetaGlucans as a therapeutic agent: Literature Review. Madridge J Food Technol. 2018; 3(2): 153-157.

doi: $10.18689 / \mathrm{mjft}-1000123$

Copyright: (c) 2018 The Author(s). This work is licensed under a Creative Commons Attribution 4.0 International License, which permits unrestricted use, distribution, and reproduction in any medium, provided the original work is properly cited.

Published by Madridge Publishers

\begin{abstract}
Functional foods have been used due to benefits promoted for patient's health. There are several types of functional foods. Thus, the prebiotics being a class used because of the health effects promoted on gastrointestinal tract. Among the prebiotic, beta-glucans ( $\left(\mathrm{BG}^{\prime} \mathrm{s}\right)$ is highlighted due to the activity in modulation of host immune response. However, besides to modulating the immune response, BG's may exert effects on metabolic parameters such as glycaemia and cholesterolemia. Such effects occur due to the formation of a gelatinous layer in the intestine, which impairs the absorption of glucose and lipids. Thus, many studies have investigated the effects of BG consumption in patients with diabetes mellitus or hypercholesterolemia. According to literature, the use of these prebiotics in glycemic and lipid metabolism control was shown to be effective mainly in diabetic patients. Such results show that beyond to the known immunomodulatory effects of BG's, exist a metabolic effect that is beneficial in prevention and may be adjuvant in the treatment of metabolic diseases.
\end{abstract}

Keywords: Beta-glucan; Prebiotic; Metabolism; Immune response; Functional foods.

\section{Introduction}

Functional foods can be considered as enriched, fortified or improved foods with one or more components that promote health benefits within a basic nutrition [1]. Because of this, such foods have been used due to their effects on disease prevention and health maintenance [2].

Among the types of functional foods are highlighted omega- 3 fortified eggs, meats with reformulated fatty acid profile, cereals, functional beverages, probiotics and prebiotics [1]. Considering these last two classes of functional foods, there is great interest in their use due to the benefits provided to the gastrointestinal tract, such as the balance of the microbiota, immunomodulation, increased bioavailability of minerals, among others factors [3].

Among the main classes of prebiotics are galacto-oligosaccharides (GOS), fructooligosaccharides (FOS), insulin and beta-glucans (BG) [4]. BG's have been widely investigated due to their immunomodulatory activity [4], as well as to the activity on the metabolism of carbohydrates and lipids [5]. In this sense, we aimed to present the functional effects of BGs on the immune response and metabolism.

\section{Probiotics}

Probiotics can be defined as microorganisms, mainly non-pathological bacteria, which are safe for consumption and which promoted beneficial effects on host's health when ingested in sufficient quantities [6]. Besides, the term probiotic, according to its Greek origin, means "in favor of life" [7].

According to Schrezenmeir and de Vrese [8], the effects of probiotics on health maintenance include: a decrease in the frequency and duration of diarrhea, the stimulation 
of humoral and cellular immunity, and the reduction of undesirable metabolites in the colon (such as ammonia and procancerogenic enzymes). In addition to these effects, the consumption of probiotics is related to reduction of infection by Helicobacter pylori, decrease of allergy symptoms, benefits on mineral metabolism, cancer prevention, intestinal constipation relief, cholesterol reduction and plasma triacylglycerol [8].

Among the action mechanisms of probiotics, we can highlight the $\mathrm{pH}$ decrease, as well as hydrogen sulfide production and increase of antimicrobial peptides in the lumen that occurs due to the metabolism of probiotic bacteria [9]. These effects create an unfavorable environment for the maintenance of pathogens $[9,10]$. In addition, probiotics can improve the intestinal barrier through modulation in the cytoskeleton that enhances cell interaction and stability [9]. The maintenance of the intestinal barrier preserves the epithelial cells that support the intestinal health, being observed that the rupture of this barrier favors the establishment of pathogens [10].

With respect to the immunomodulatory effects of probiotics, a possible mechanism is the stimulation of Immunoglobulin A $(\lg A)$ and relief of inflammatory responses in the intestine [11]. Besides that, some probiotics are able to interact with immune cells, or their receptors, promoting increased phagocytic activity, increasing intraepithelial lymphocyte proliferation, and modulation of Th1 and Th2 responses [6].

Thus, considering the importance of probiotics for health, studies have investigated the effects of the consumption of these microorganisms concomitantly with their energy substrates [12,13]. These substrates are called prebiotics, and are defined as non-digestible food ingredients that cause health improvement through stimulation in the growth or activity of the microbiota in the gastrointestinal tract [13].

\section{Prebiotics}

Another definition for prebiotic includes it as a selectively fermentable ingredient that promotes specific changes in composition and activity of the intestinal microbiota and promotes benefits to the health's host [14]. The combination of probiotics and prebiotics in a commercial product, in order to promote beneficial effects to host by improving the microbiota of the gastrointestinal tract, is defined as symbiotic [15].

The consumption of prebiotics alone has shown beneficial effects on health $[16,17]$. Such effects include a decrease in the prevalence and duration of infectious agents and antibioticassociated diarrhea; improvement of the bioavailability and absorption of minerals (calcium, magnesium and possibly iron); reduction of inflammation and symptoms associated with inflammatory bowel disease as well as colon cancer; besides weight loss and prevention of obesity due satiety promoting [16].

In addition, some oligosaccharides and polysaccharides promote prebiotic activity [14]. Among them, it highlighted fruit-oligosaccharides (FOS), galacto-oligosaccharides (GOS), insulin, pyrodextrins and glucans $[18,19]$. Glucans are the major structural components of the cell wall of fungi, grass and some bacteria [20]. Among the glucans, beta-glucans (BG) have been highlighted as prebiotics used as modulators both of the immune response [21], as well as lipid and carbohydrate metabolism [5].

\section{Beta-Glucans (BG)}

BG's are non-starch polysaccharides found in cell wall structure of fungi, mushrooms and yeasts [22]. Some cereals such as oats, rye and barley [23], as well as bacteria [24] also have $B G$ in their structure. These compounds promote benefits on metabolic and immunological parameters and such actions have been demonstrated in chronic diseases such as diabetes mellitus [22,25], dyslipidemias [26] and infections [27,28].

The chemical structure of the BG contains a central linear bond of $\beta$-type (1-3), formed by units of glucose connected in the main chain, that differ according to their length and ramifications [29]. The BG's isolated from grasses have a linear structure and presents branching with $\beta$-bonds (1-4), and those from fungi and yeasts have $\beta$-bonds (1-6), which confer different biological actions of these polysaccharides [22].

The peculiarity of the actions of each type of BG varies with its conformation, molecular mass, solubility and the degree of positioning of its branches [30]. BG's with lower branching and lower polymerization (such BG's from plants with $\beta$ (1-4) binding) are characterized as soluble, whereas insoluble ones such as BG's isolated from fungi with type bonds $\beta$ (1-6), have higher polymerization and greater number of branches [30].

Low-weight BG's are usually inactive, while those of intermediate weight have biological actions in vivo, and their efficacy is low at cellular levels [27]. On the other hand, those BG with high molecular weight can activate leukocytes directly, stimulating their phagocytic, cytotoxic and antimicrobial activity [27].

The chemical structure of BG's isolated from oats presents a linear structure formed by glucose units communicated by $\beta$ (1-3) and $\beta$ (1-4) bonds, having short branches. The $\beta(1-4)$ bonds correspond to $70 \%$ of the glycosidic bonds, and appear in sequence of two or three glucose units interrupted by a $\beta$ (1-3) [31].

BGs from oats have beneficial characteristics in metabolic parameters, such as cholesterol reduction and plasma triglycerides, and possibly act in the prevention and treatment of diabetes mellitus by lowering glycemic levels [32]. However, studies investigate the effects of these prebiotics on the immune response $[21,33,34]$. Such activity is observed in both innate and adaptive immunity, benefiting the anticarcinogenic action [21,33], besides presenting chemopreventive action [33].

As a consequence of its immunomodulatory effect, oats BG supports in the prevention of bacterial infections such as Candida albicans, as well as from protozoa such as Toxoplasma gondii [35] and resistant bacteria [4,36]. In addition, BG favors phagocytosis and the production of proinflammatory cytokines by macrophages stimulating neutrophils and monocytes, thus leading to an improvement in the immune response [37]. 
However, the effects of BGs exceed immunomodulatory parameters, and several studies have also demonstrated their efficacy in metabolic functions, such as hypocholesterolemic and hypoglycemic effect [33,38-40].

Lo et al. [40] demonstrated that BGs from oat and fungus reduce glycaemia when consumed orally. The mechanisms that explain this effect are related to the formation of a gelatinous layer that acts as a barrier that hinders the absorption of glucose and lipids [39], decreasing glycaemia and cholesterolemia in humans and animals [26,41-43].

This gelatinous layer promotes an increase in the viscosity of the contents formed in the intestinal lumen, acting as a sieve that filters small molecules and slowing the digestion and absorption of some nutrients and the large molecules are not filtered and pass directly through the intestine [39]. There is also the hypothesis that this gelatinous layer delays the interaction of starch and its digestive enzyme causing the reduction in absorption of carbohydrates and consequently the reduction of glycaemia [44].

The effect of this selection causes a decrease in glucose uptake by enterocytes [45], decreasing blood glucose concentration [39] and increasing insulin sensitivity. Such effects may aid in treatment of metabolic disorders such as diabetes, as well as other diseases associated with these illnesses [46]. In addition, studies suggest that this viscosity formed by the BGs reduces the levels of total cholesterol, low density lipoprotein $(L D L-C)$ and triacylglycerol, increasing the rate of high density lipoproteins ( $\mathrm{HDL}-\mathrm{C})$, justifying the prevention of cardiovascular diseases $[42,47,48]$. Additionally, the formation of the gelatinous layer induces a sensation of satiety caused by delayed gastric emptying reducing the need for more food intake and altering energy consumption, thus causing weight loss $[42,49,50]$.

Apparently, BG doses below $3.0 \mathrm{~g} /$ patient/day are not efficient in improve glycemic control in diabetic patients [42,51,52]. However, BG doses above $6.0 \mathrm{~g} /$ patient/day reduced glycaemia and insulin concentration in the study of Tappy et al. [41].

Regarding the lipid profile was observed that doses between 3.0 and $6.0 \mathrm{~g} /$ patient/day reduced serum concentrations of triglycerides, total cholesterol $[42,53,54]$ and LDL-C $[42,53]$. The mechanism involved in this alteration may be associated with decreased cholesterol uptake and bile acid reabsorption in the gut. Thus, the reduction of these substances in enterohepatic circulation leads to an increase in the conversion of cholesterol to bile acids [55].

It has been reported that BG inhibits in vitro the uptake of long chain fatty acids into the intestinal tissue when these lipids are in high concentration [56]. Furthermore, these fibers reduced the risk of cardiovascular and metabolic diseases by mediating the inflammatory process $[57,58]$. The hypotheses for these mechanisms demonstrate that BG's decreases oxidation of glucose and lipids by promoting a healthy intestinal environment; preventing inflammation by altering the adipocytokines of adipose tissue and increasing the hepatic whole circulation of lipids and lipophilic compounds
[59]. Thus, these mechanisms demonstrate the inverse association between fiber intake and levels of inflammatory biomarkers in diabetic, hypertensive and obese patients $[59,60]$. These particularities in the action of BG's arise from their physicochemical properties (molecular weight and solubility), their predisposition to water retention, viscosity, emulsification, fermentability, and resistance to degradation by intestinal bacteria and their propensity to absorb nutrients [52].

Regarding their toxicity, when orally administered during four weeks, BGs showed no signs of toxicity, nor when administered in large quantities $[61,62]$.

\section{Conclusions}

A large part of the studies presented exemplify the beneficial effects of BG's on both immunological and metabolic parameters. In this way, the use of these prebiotics can be made, within the safe limits, especially in order to maintain glycemic and lipid profile within normality, besides attenuating inflammatory and infectious symptoms.

\section{References}

1. Bigliardi B, Galati F. Innovation trends in the food industry: The case of functional foods. Trends Food Sci Technol. 2013; 31(2): 118-129. doi: 10.1016/J.TIFS.2013.03.006

2. Marinangeli CPF, Jones PJH. Functional food ingredients as adjunctive therapies to pharmacotherapy for treating disorders of metabolic syndrome. Ann Med. 2010; 42(5): 317-333. doi: 10.3109/07853890.2010.484026

3. Roberfroid MB. Prebiotics and probiotics: are they functional foods? Am J Clin Nutr. 2000; 71(6): 1682S-1687S. doi: 10.1093/ajcn/71.6.1682S

4. Vetvicka V. Glucan-immunostimulant, adjuvant, potential drug. World J Clin Oncol. 2011; 2(2): 115-119. doi: 10.5306/wjco.v2.i2.115

5. De Natale $C$, Minerva $V$, Patti L, et al. Effects of baked products enriched with $n-3$ fatty acids, folates, $\beta$-glucans and tocopherol in patients with mild mixed hyperlipidemia. J Am Coll Nutr. 2012; 31(5): 311-319.

6. Sanders ME. Probiotics: considerations for human health. Nutr Rev. 2003; 61(3): 91-99.

7. Fuller R. History and development of probiotics. Probiotics. 1992; 1-8. doi: 10.1007/978-94-011-2364 8_1

8. Schrezenmeir J, de Vrese M. Probiotics, prebiotics, and synbioticsapproaching a definition. Am J Clin Nutr. 2001; 73(2): 361s-364s. doi: 10.1093/ajcn/73.2.361s

9. Ng SC, Hart AL, Kamm MA, Stagg AJ, Knight SC. Mechanisms of action of probiotics: Recent advances. Inflamm Bowel Dis. 2009; 15(2): 300-310. doi: 10.1002/ibd.20602

10. Madsen K, Cornish A, Soper P, et al. Probiotic bacteria enhance murine and human intestinal epithelial barrier function. Gastroenterology. 2001; 121(3): 580-591.

11. Isolauri $E$, Sütas $Y$, Kankaanpää $P$, Arvilommi $H$, Salminen S. Probiotics: effects on immunity. Am J Clin Nutr. 2001; 73(2): 444s-450s. doi: 10.1093/ ajcn/73.2.444s

12. Brassart $D$, Schiffrin EJ. The use of probiotics to reinforce mucosal defence mechanisms. Trends Food Sci Technol. 1997; 8(10): 321-326. doi: 10.1016/ S0924-2244(97)01071-6

13. Tuohy KM, Probert HM, Smejkal CW, Gibson GR. Using probiotics and prebiotics to improve gut health. Drug Discov Today. 2003; 8(15): 692-700.

14. Gibson GR, Probert HM, Loo J Van, Rastall RA, Roberfroid MB. Dietary modulation of the human colonic microbiota: updating the concept of prebiotics. Nutr Res Rev. 2004; 17(2): 259. doi: 10.1079/NRR200479 
15. Oliveira RPS, Florence ACR, Silva RC, et al. Effect of different prebiotics on the fermentation kinetics, probiotic survival and fatty acids profiles in nonfat symbiotic fermented milk. Int J Food Microbiol. 2009; 128(3): 467472. doi: 10.1016/J.IJFOODMICRO.2008.10.012

16. Brownawell AM, Caers W, Gibson GR, et al. Prebiotics and the Health Benefits of Fiber: Current Regulatory Status, Future Research, and Goals. J Nutr. 2012; 142(5): 962-974. doi: 10.3945/jn.112.158147

17. Conway PL. Prebiotics and human health: The state-of-the-art and future perspectives. Näringsforskning. 2001; 45(1): 13-21. doi: 10.3402/fnr. v45i0.1784

18. Russo $P$, López $P$, Capozzi $V$, et al. Beta-glucans improve growth, viability and colonization of probiotic microorganisms. Int J Mol Sci. 2012; 13(5): 6026-6039. doi: 10.3390/ijms13056026

19. Macfarlane GT, Cummings JH. Probiotics and prebiotics: can regulating the activities of intestinal bacteria benefit health? BMJ. 1999; 318(7189): 999-1003.

20. Cohen NR, Tatituri RVV, Rivera A, et al. Innate Recognition of Cell Wall $\beta$-Glucans Drives Invariant Natural Killer T Cell Responses against Fungi. Cell Host Microbe. 2011; 10(5): 437-450. doi: 10.1016/j.chom.2011.09.011

21. Masuda $Y$, Inoue $H$, Ohta $H$, Miyake $A$, Konishi $M$, Nanba $H$. Oral administration of soluble $\beta$-glucans extracted from Grifola frondosa induces systemic antitumor immune response and decreases immunosuppression in tumor-bearing mice. Int J Cancer. 2013; 133(1): 108-119. doi: 10.1002/ijc.27999

22. Rahar S, Swami G, Nagpal N, Nagpal M, Singh G. Preparation, characterization, and biological properties of $\beta$-glucans. J Adv Pharm Technol Res. 2011; 2(2): 94. doi: 10.4103/2231-4040.82953

23. Volman JJ, Ramakers JD, Plat J. Dietary modulation of immune function by $\beta$-glucans. Physiol Behav. 2008; 94(2): 276-284. doi: 10.1016/J. PHYSBEH.2007.11.045

24. Gacto M, Vicente-Soler J, Cansado J, Villa TG. Characterization of an extracellular enzyme system produced by Micromonospora chalcea with lytic activity on yeast cells. J Appl Microbiol. 2000; 88(6): 961-967.

25. Silva $\mathrm{V}$ de $\mathrm{O}$, Lobato RV, Andrade EF, et al. $\beta$-Glucans (Saccharomyces cereviseae) Reduce Glucose Levels and Attenuate Alveolar Bone Loss in Diabetic Rats with Periodontal Disease. PLoS One. 2015; 10(8): e0134742. doi: 10.1371/journal.pone. 0134742

26. King DE. Dietary fiber, inflammation, and cardiovascular disease. Mol Nutr Food Res. 2005; 49(6): 594-600. doi: 10.1002/mnfr.200400112

27. Akramiene D, Kondrotas A, Didziapetriene J, Kevelaitis E. Effects of betaglucans on the immune system. Medicina (Kaunas). 2007; 43(8): 597-606.

28. Sandvik A, Wang YY, Morton HC, Aasen AO, Wang JE, Johansen FE. Oral and systemic administration of $\beta$-glucan protects againstlipopolysaccharideinduced shock and organ injury in rats. Clin Exp Immunol. 2007; 148(1): 168-177. doi: 10.1111/j.1365-2249.2006.03320.x

29. Sonck $E$, Stuyven $E$, Goddeeris $B$, Cox E. The effect of $\beta$-glucans on porcine leukocytes. Vet Immunol Immunopathol. 2010; 135(3-4): 199-207. doi: 10.1016/j.vetimm.2009.11.014

30. Mantovani MS, Bellini MF, Angeli JPF, Oliveira RJ, Silva AF, Ribeiro LR. $\beta$-Glucans in promoting health: Prevention against mutation and cancer. Mutat Res Mutat Res. 2008; 658(3): 154-161. doi: 10.1016/j.mrrev.2007.07.002

31. Fujita $A H$, Figueroa MOR. Centesimal composition and b- glucan content in cereals and derivatives. Ciênc Tecnol Food. 2003; 23(2): 116-120. doi: 10.1590/S0101-20612003000200003

32. Cavallero A, Empilli $S$, Brighenti $F$, Stanca AM. High $(1 \rightarrow 3,1 \rightarrow 4)$ - $\beta$-Glucan Barley Fractions in Bread Making and their Effects on Human Glycemic Response. J Cereal Sci. 2002; 36(1): 59-66. doi: 10.1006/JCRS.2002.0454

33. da Silva AF, Oliveira RJ, Niwa AM, D'Epiro GFR, Ribeiro LR, Mantovani MS. Anticlastogenic effect of $\beta$-glucan, extracted from Saccharomyces cerevisiae, on cultured cells exposed to ultraviolet radiation. Cytotechnology. 2013; 65(1): 41-48. doi: 10.1007/s10616-012-9448-z

34. Chen J, Zhang XD, Jiang Z. The application of fungal $\beta$-glucans for the treatment of colon cancer. Anticancer Agents Med Chem. 2013; 13(5): 725-730.
35. Estrada A, Yun C, Van Kessel A, Li B, Hauta S, Laarveld B. Immunomodulatory Activities of Oat $\beta$-Glucan In Vitro and In Vivo. Microbiol Immunol. 1997; 41(12): 991-998. doi: 10.1111/j.1348-0421.1997.tb01959.x

36. Rice PJ, Adams EL, Ozment-Skelton $T$, et al. Oral Delivery and Gastrointestinal Absorption of Soluble Glucans Stimulate Increased Resistance to Infectious Challenge. J Pharmacol Exp Ther. 2005; 314(3): 1079-1086. doi: 10.1124/jpet.105.085415

37. Rubin-Bejerano I, Abeijon C, Magnelli P, Grisafi P, Fink GR. Phagocytosis by Human Neutrophils Is Stimulated by a Unique Fungal Cell Wal Component. Cell Host Microbe. 2007; 2(1): 55-67. doi: 10.1016/j. chom.2007.06.002

38. Doria MCS, Lipp MEN, Silva DF. O The use of acupuncture in the symptomatology of stress. Psychology: Science and Profession. 2012; 32(1): 34-51. doi: 10.1590/S1414-98932012000100004

39. Reyna NY, Cano C, Bermúdez VJ, et al. Sweeteners and beta-glucans improve metabolic and anthropometrics variables in well controlled type 2 diabetic patients. Am J Ther. 2003; 10(6): 438-443.

40. Lo HC, Tsai FA, Wasser SP, Yang JG, Huang BM. Effects of ingested fruiting bodies, submerged culture biomass, and acidic polysaccharide glucuronoxylomannan of Tremella mesenterica Retz.:Fr. on glycemic responses in normal and diabetic rats. Life Sci. 2006; 78(17): 1957-1966. doi: 10.1016/j.lfs.2005.08.033

41. Tappy L, Gügolz E, Würsch P. Effects of breakfast cereals containing various amounts of beta-glucan fibers on plasma glucose and insulin responses in NIDDM subjects. Diabetes Care. 1996; 19(8): 831-834. doi: 10.2337/diacare.19.8.831

42. Liatis $S$, Tsapogas $P$, Chala $E$, et al. The consumption of bread enriched with betaglucan reduces LDL-cholesterol and improves insulin resistance in patients with type 2 diabetes. Diabetes Metab. 2009; 35(2): 115-120. doi: 10.1016/j.diabet.2008.09.004

43. Vieira Lobato R, De Oliveira Silva V, Francelino Andrade E, et al. Metabolic effects of $\beta$-glucans (Saccharomyces cerevisae) per os administration in rats with streptozotocin-induced diabetes. Nutr Hosp. 2015; 32(1): 256264. doi: $10.3305 / \mathrm{nh} .2015 .32 .1 .9013$

44. Battilana $P$, Ornstein $K$, Minehira $K$, et al. Mechanisms of action of $\beta$-glucan in postprandial glucose metabolism in healthy men. Eur J Clin Nutr. 2001; 55(5): 327-333. doi: 10.1038/sj.ejcn.1601160

45. De Paula ACCFF, Sousa RV, Figueiredo-Ribeiro RCL, Buckeridge MS Hypoglycemic activity of polysaccharide fractions containing betaglucans from extracts of Rhynchelytrum repens (Willd.) C.E. Hubb. Poaceae. Brazilian J Med Biol. 2005; 38(6): 885-893. doi: 10.1590/S0100$879 \times 2005000600010$

46. Würsch P, Pi-Sunyer FX. The role of viscous soluble fiber in the metabolic control of diabetes. A review with special emphasis on cereals rich in betaglucan. Diabetes Care. 1997; 20(11): 1774-1780.

47. Jenkins AL, Jenkins DJA, Zdravkovic $U$, Würsch $P$, Vuksan V. Depression of the glycemic index by high levels of beta-glucan fiber in two functional foods tested in type 2 diabetes. Eur J Clin Nutr. 2002; 56(7): 622-628. doi: 10.1038/sj.ejcn.1601367

48. Gao R, Wang Y, Wu Z, Ming J, Zhao G. Interaction of barley $\beta$-glucan and tea polyphenols on glucose metabolism in streptozotocin-induced diabetic rats. J Food Sci. 2012; 77(6): 128-134. doi: 10.1111/j.1750-3841.2012.02688.x

49. Choi JS, Kim H, Jung MH, Hong S, Song J. Consumption of barley betaglucan ameliorates fatty liver and insulin resistance in mice fed a high-fat diet. Mol Nutr Food Res. 2010; 54(7): 1004-1013. doi: 10.1002/ mnfr.200900127

50. Kim JW, Cho HR, Moon SB, Kim KY, Ku S. Synergic effects of bitter melon and $\beta$-Glucan composition on STZ-induced rat diabetes and its complications. J Microbiol Biotechnol. 2012; 22(1): 147-155.

51. Cugnet-Anceau C, Nazare JA, Biorklund M, et al. A controlled study of consumption of beta-glucan-enriched soups for 2 months by type 2 diabetic free-living subjects. Br J Nutr. 2010; 103(3): 422-428. doi: 10.1017/ S0007114509991875 
52. Francelino Andrade $E$, Vieira Lobato $R$, Vasques Araújo T, Gilberto Zangerônimo M, Vicente Sousa R, José Pereira L. Effect of beta-glucans in the control of blood glucose levels of diabetic patients: A systematic review. Nutr Hosp. 2014; 31(1): 170-177. doi: 10.3305/nh.2015.31.1.7597

53. Pick ME, Hawrysh ZJ, Gee MI, Toth E, Garg ML, Hardin RT. Oat Bran Concentrate Bread Products Improve Long-Term Control of Diabetes: A Pilot Study. J Am Diet Assoc. 1996; 96(12): 1254-1261. doi: 10.1016/S00028223(96)00329-X

54. Kabir M, Oppert JM, Vidal H, et al. Four-week low-glycemic index breakfast with a modest amount of soluble fibers in type 2 diabetic men. Metabolism. 2002; 51(7): 819-826.

55. Chang HC, Huang CN, Yeh DM, Wang SJ, Peng CH, Wang CJ. Oat prevents obesity and abdominal fat distribution, and improves liver function in humans. Plant Foods Hum Nutr. 2013; 68(1): 18-23. doi: 10.1007/s11130013-0336-2

56. Drozdowski LA, Reimer RA, Temelli F, Bell RC, Vasanthan T, Thomson ABR $\beta$-Glucan extracts inhibit the in vitro intestinal uptake of long-chain fatty acids and cholesterol and down-regulate genes involved in lipogenesis and lipid transport in rats. J Nutr Biochem. 2010; 21(8): 695-701. doi: 10.1016/j.jnutbio.2009.04.003
57. Liu S, Buring JE, Sesso HD, Rimm EB, Willett WC, Manson JE. A prospective study of dietary fiber intake and risk of cardiovascular disease among women. J Am Coll Cardiol. 2002; 39(1): 49-56. doi: 10.1016/S07351097(01)01695-3

58. Liu S. Whole-grain foods, dietary fiber, and type 2 diabetes: searching for a kernel of truth. Am J Clin Nutr. 2003; 77(3): 527-529. doi: 10.1093/ ajcn/77.3.527

59. King DE, Mainous AG, Egan BM, Woolson RF, Geesey ME. Fiber and C-reactive protein in diabetes, hypertension, and obesity. Diabetes Care. 2005; 28(6): 1487-1489.

60. Ma Y, Hébert JR, Li W, et al. Association between dietary fiber and markers of systemic inflammation in the Women's Health Initiative Observational Study. Nutrition. 2008; 24(10): 941-949. doi: 10.1016/j.nut.2008.04.005

61. Jonker D, Hasselwander O, Tervilä-Wilo A, Tenning PP. 28-Day oral toxicity study in rats with high purity barley beta-glucan (Glucagel). Food Chem Toxicol. 2010; 48(1): 422-428. doi: 10.1016/j.fct.2009.10.034

62. Túrmina JA, Carraro E, Alves da Cunha MA, et al. Toxicological assessment of $\beta$-(1-6)-glucan (lasiodiplodan) in mice during a 28-day feeding study by gavage. Molecules. 2012; 17(12): 14298-14309. doi: 10.3390/ molecules171214298 